\title{
ACTIVITY PATTERNS OF RIVER OTTERS IN THE OXBOW BEND VICINITY, GRAND TETON NATIONAL PARK
}

\author{
JOSEPH G. HALL \ DEPARTMENT OF BIOLOGY \\ SAN FRANCISCO STATE UNIVERSITY $\uparrow$ SAN FRANCISCO
}

\section{$\uparrow \quad$ OBJECTIVES}

Goals of the project were to obtain information on daily movements and activity patterns of River otters (Lutra canadensis), particularly nocturnal activity, to supplement data on diumal activity obtained from a previous study. Of special interest was to determine whether or not nocturnal peaks in activity occur which are similar to those seen by day. Additionally, observations of any evidence of fidelity to specific habitat sites documented in previous years were to be recorded.

\section{$\downarrow \quad$ METHODS}

Intensive daytime observations of otters and of their sign (tracks, latrines and dens) in the Oxbow Bend area were made for the first two weeks of the study period. This was done primarily by canoe and at all times of day. Based on this initial survey, automatic cameras equipped with data-backs to record exposure times were set out at the most promising sites. These cameras were actuated by any animal stepping on a treadle-switch buried in a trail or latrine site. Each camera was revisited daily to check on the condition of its batteries and for records of exposures.

\section{$\uparrow \quad$ RESULTS}

During the month of July, six different sites were monitored with four cameras for a total of 1,200 camera-hours. In this period, 25 photographs of otters were obtained (Fig. 1). Otters are highly social and playful animals, a trait that is documented by almost all the photographs showing at least two to four animals. This trait makes it necessary to define such a multiple encounter as a single "visit" or a "passage". The number of separate visits at each site is the most appropriate activity-unit. On a couple of occasions a group of otters stayed at a given site for several minutes, romping with each other and repeatedly stepping on the treadle-switch, thus actuating the camera many times in a short period of time. As a rule of thumb, I did not count any photograph to be a record of a separate visit unless it was taken at least 30 minutes after the preceding photograph. Using this criterion to correct for closely-spaced exposures, the 25 photographs obtained recorded only 10 events that qualified as independent visits. It is sobering to realize that, on the average, five 24-hour days of monitoring were required to record each visit. Increasing the number of cameras in the field would be a logical way to improve efficiency.

Four visits occurred during the day and six occurred at night. There was a wide spread among the nighttime visits - from 2020 to 0540 . Obviously, however, no peaks in nocturnal activity could be demonstrated with a sample size of six. Conceivably, the ratio of four daytime visits to six nighttime visits might reflect a real difference between diurnal and nocturnal activity. Again, a larger sample size would be needed to permit one to justify drawing that conclusion. 
Still another conclusion that is suggested but would need more data to confirm is that a group of otters has a habitual circuit that is run in the same direction each time. The seven visits recorded on a trail on the main island in the Oxbow Bend showed all otters traveling in a southerly direction. Two photographs taken a day apart even depicted what appeared to be the same family group of three otters in the same orientation to each other - adult to the left of two juveniles.

In additon to otters, the cameras recorded a ground squirrel (Spermophilus sp.), a badger (Taxidea taxus) and two curious canoeists who evidently could not resist investigating the strange-looking package on a tripod. One of my main concerns in using this equipment was the potential for vandalism. Fortunately, it turned out not to be a problem.

We observed an abundance of otter sign and otter activity (including discovery of an occupied otter den) on the northwest comer of the main island. Even more activity was observed at a site on the western end of the northern border of the Oxbow. Both of these areas were focal points for activity over a decade ago and indicate that there may be a tradition of use, passed down from one generation of otters to another.
The main conclusion of this study has been that there is no shortage of interesting facets of otter natural history waiting to be studied. But we need much more data and many more observations before we can detect presence or absence of trends and be confident in drawing defensible conclusions about other behavioral features of these fascinating mammals.

\section{$\uparrow \quad$ ACKNOWLEDGEMENTS}

I wish to acknowledge the substantial help in the field provided by my wife, Betty, by my assistant, Kathleen McGinley, by Peter Mui (who also gave me invaluable advice on operation of the monitor cameras) and by friends and other members of my family who visited the Park.

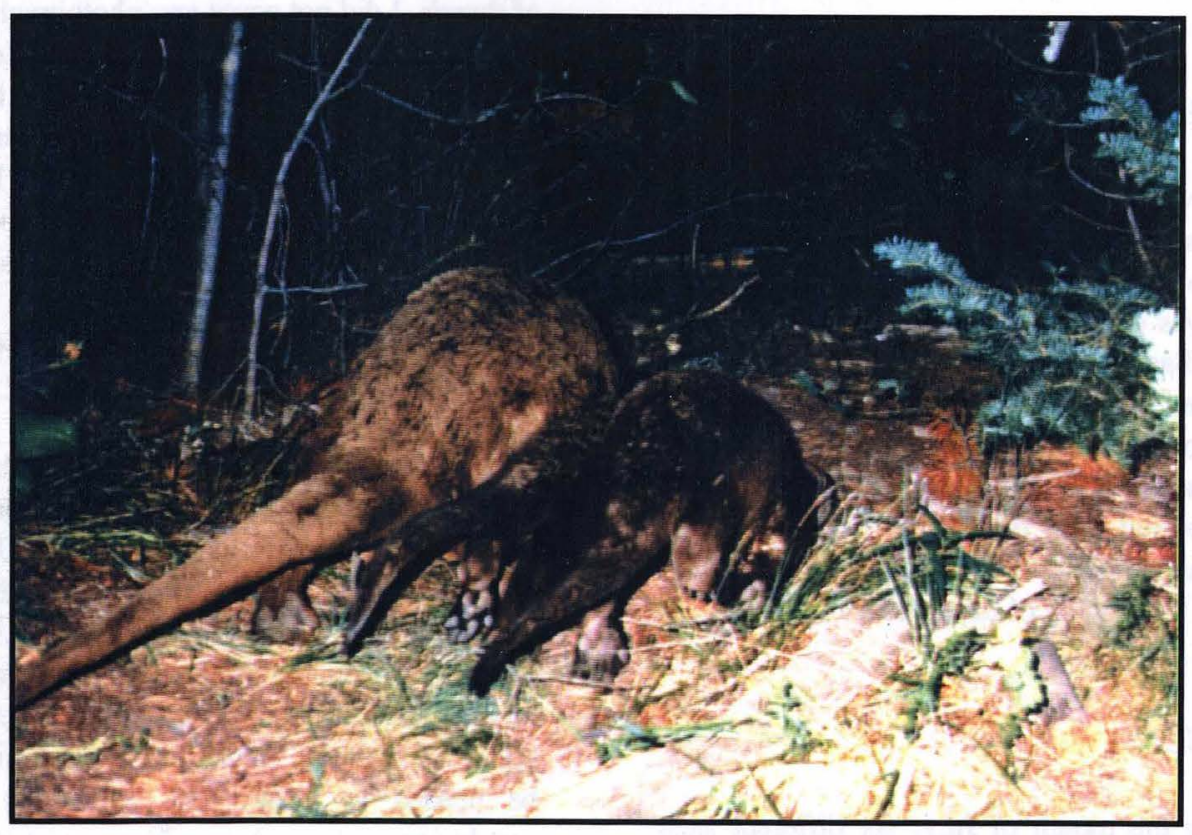

